\title{
EL CARTULARIO DEL TEMPLE DE LA ENCOMIENDA DE NOVILLAS (SIGLO XII). CUESTIONES SOBRE LA PRIMERA ANDADURA DE LA ORDEN EN NAVARRA
}

\author{
POR \\ JULIA PAVÓn BENITO ${ }^{1}$ \\ Universidad de Navarra
}

\section{RESUMEN}

El Cartulario del Temple de la encomienda de Novillas, del último tercio del siglo XII, depositado en el Archivo Histórico Nacional (L.595), contiene un amplio repertorio documental sobre la primera etapa de la orden del Temple en el valle medio del Ebro. Esta temprana pieza compilatoria apenas ha sido valorada en su conjunto como una elaboración intencional de la memoria institucional de los templarios, dentro de un espacio regional convulso, y donde la presencia y actividades sociales y económicas de la orden tuvieron una especial trascendencia.

Palabras CLAVE: Orden del Temple; Cartulario de Novillas (s. XII); Templarios en el reino de Navarra y reino de Aragón en el siglo XII.

\section{THE CARTULARY OF KNIGHTS TEMPLAR OF THE PRECEPTORY OF NOVILLAS $\left(12^{\text {TH }}\right.$ CENTURY). ON THE SETTLEMENT OF THE ORDER OF THE TEMPLE IN THE MIDDLE EBRO VALLEY}

\begin{abstract}
The Cartulary of Knights Templar of the Preceptory of Novillas, dating back to the last decades of the 12th century and deposited in the National Historical Archive in Madrid (L.595), contains a broad range of documents about the initial phase of the Order of the Temple in the valley of Middle Ebro. This early compilation has hardly been studied as a whole and as a deliberate elaboration of the Knights' Templar institutional memory, created in a context of regional upheavals in which the order's presence and its socioeconomic activity was of particular significance.
\end{abstract}

KEY WORDS: Order of the Temple; Novillas Cartulary ( $12^{\text {th }}$ century); Knights Templar in the Kingdom of Navarre and Kingdom of Aragon in the 12 th century.

Cómo CitAR eSte artículo / CITATION: Pavón Benito, J. 2018. «El Cartulario del Temple de la encomienda de Novillas (siglo XII). Cuestiones sobre la primera andadura de la Orden en el valle medio del Ebro». Hispania Sacra 70, 142: 433-443. https://doi. org/10.3989/hs.2018.029

Recibido/Received 23-01-2017

Aceptado/Accepted 28-02-2017

El Archivo Histórico Nacional de Madrid custodia en la sección de "Órdenes Militares. Orden del Temple», y dentro de la Colección Códices y Cartularios, un Cartulario del Temple con la signatura. L. 595, que a finales del siglo XVIII fue restaurado, revisado e indexado por Juan Antonio Fernández (1752-1814), notario del tribunal eclesiástico del obispado de Tudela y archivero general de la orden de Santiago, durante su etapa al servicio de la orden de San Juan de Jerusalén

\footnotetext{
1 jpavon@unav.es/ORCIDiD:http://orcid.org/0000-0001-5806-6094
}

en Zaragoza, entre 1793 y 1809 . El cartulario se supone que fue iniciado y mayormente realizado en pergamino en tiempos del maestre provincial en la Provenza e Hispania, Arnaldo de Torroja (1169, oct.-1181, mar.). Recoge un total de cuatrocientas cuarenta y cuatro escrituras entre copias -algunas duplicadas-, noticias, extractos documentales y listas de cofrades concernientes a la actividad de la orden del Temple durante su primera etapa de establecimiento en el valle medio del Ebro, desplegada desde su sede de Novillas (Aragón) durante las décadas centrales del siglo XII. 
Este manuscrito, inventariado por Joseph Delaville Le Roulx en el Archivo General Central de Alcalá de Henares, en torno a 1893, fue sucintamente descrito por aquel entonces, siendo objeto de una atención posterior por parte de la archivera Áurea L. Javierre Mur, que detalló la historia y fondos de la Castellanía de Amposta pertenecientes al archivo de San Juan de los Panetes en un artículo de 1948. Los contenidos de este cartulario habían sido anteriormente transcritos, en parte, por el marqués d'Albon, en su monografía de 1913 del Cartulaire Général de l'Ordre du Temple (1119?-1150), al igual que haría tiempo después José María Lacarra de Miguel para su edición de los «Documentos para la reconquista y repoblación del valle del Ebro», publicada en tres series, en la revista de Estudios de Edad Media de la Corona de Aragón, entre 1946 y 1952. No obstante, excepto en el caso de A. L. Javierre, jefa de la Sección de Órdenes Militares del AHN, entre 1949 y 1968, que procedió a una más detallada descripción del códice, que incluía incluso la copia del índice realizado por J. A. Fernández, no se ha realizado hasta la fecha un nuevo estudio de esta pieza. ${ }^{2}$ Algunos breves apuntes e investigaciones complementarias con respecto al códice harían años más tarde Santos García Larragueta, Antonio Ubieto, Marina González Miranda - que hizo un catálogo de sus documentos (1954)—, María Luisa Ledesma y Ana Isabel Lapeña, cuya tesis de licenciatura versó sobre la realidad dominical de la encomienda templaria de Novillas, incluyendo un apéndice documental inédito extraído de este manuscrito, y publicando posteriormente tan solo su estudio previo en la revista Cuadernos de Estudios Borjanos (1979). Más recientemente, Salvador Remírez Vallejo ha considerado y examinado un conjunto textual relativo a la actividad templaria alrededor de la encomienda de Cintruénigo y de alguno de sus linajes del siglo XII. En la actualidad un equipo de la Universidad de Navarra prepara una edición para 2019 de sus diplomas referidos al reino de Navarra. ${ }^{3}$

A la vista de lo expuesto, el objetivo de este artículo es el de plantear una primera valoración de este códice del Temple, uno de los más antiguos de la orden en Europa, a partir de las características formales, estructurales y de gestación gráficotextual del mismo, esto es sus principales rasgos como producto cultural de una época e institución concretas. Este análisis se concibe como un punto de partida para bosquejar, algunas líneas de reflexión acerca de la tipología de sus contenidos documentales - textos en su mayoría inéditosy su finalidad, que sin duda llevarán a calibrar, tanto directa, como indirectamente, distintas cuestiones políticas, sociales y patrimoniales acerca de la primera andadura de esta orden en la Península Ibérica, y más concretamente en el valle medio del Ebro y en la franja meridional del reino de Pamplona-Navarra. La información de los actos jurídicos, en su mayoría vinculados a la gestión de la encomienda de Novillas, epicentro del triángulo fronterizo dibujado por los principales reinos hispanos enfrentados después de la muerte de Alfonso I el Batallador durante al menos cuatro décadas, referirá considerar dichos textos, al mismo tiempo, como instrumentos de poder o control para entender el despliegue inicial de la institución templaria en las tierras peninsulares. ${ }^{4}$

\footnotetext{
2 Cruz Herranz 2011: 737-738.

3 Bonet Donato, M. y Pavón Benito, J. (dirs.). El Temple en Navarra. Historia y documentos.

4 Chastang 2006 y Escalona et Sirantoine 2013.
}

Sin embargo, más allá de una memoria explicativa de las habituales actividades contractuales, la existencia del cartulario y sus contenidos podrán ser interpretados dentro de una lógica intrínseca de los poderes y actores secundarios implicados en la reordenación y acomodación de los espacios recuperados ante el Islam.

\section{CARACTERÍSTICAS DEL CÓDICE: DATACIÓN, AUTORÍA, HISTORIA Y ESTRUCTURA}

El Códice L. 595 del AHN de la sección «Órdenes Militares. Orden del Temple. Cartularios de la orden del Temple», antiguamente clasificado con la referencia "Códice 691» realizado en pergamino, con un total de 199 folios, tiene un formato original de $210 \times 140 \mathrm{~mm}$, un tamaño cómodamente manejable y transportable. ${ }^{5}$ Asimismo recoge en sus páginas iniciales un añadido en papel, una explicación introductoria manuscrita realizada por J. A. Fernández, conocido también como el librero, ${ }^{6}$ y un "Índice alfabético de los pueblos de que se hace expresión en el presente cartulario, y de los años en que se otorgaron sus escrituras, con el número a que se corresponde cada una de ellas», realizado por el mismo archivero. ${ }^{7}$

\section{Datación y autoría}

No es fácil establecer una datación concreta del momento de elaboración de esta colección memorística objeto de esta investigación. El conjunto se corresponde a uno de los compendios más antiguos del Temple en la Península Ibérica y de Europa occidental, ${ }^{8}$ junto con el manuscrito L. 665 del AHN, que contiene la relación de los miembros de la Hermandad o Cofradía de la Orden, y Milicia de caballeros del Templo de Salomón de Jerusalén en los dominios de España, ambos realizados durante el último tercio del siglo XII, y con características formales y gráficas muy similares. Al parecer, tal y como indica J. A. Fernández, el de Novillas se comenzó durante el maestrazgo provincial del leridano Arnaldo de Torroja (1169, oct.-1181, mar.) ${ }^{9}$ si bien pudieron añadirse textos posteriores, cerrando el arco cronológico documental que se inicia en 1117 , con una copia datada en

5 Uno de los aspectos estudiados sobre la temprana producción de cartularios, por parte de las Órdenes Militares en la Provenza occidental y el Bajo Ródano, está en relación con la utilidad de unos repertorios de carácter funcional por parte de unas nuevas instituciones con mayor movilidad y necesidades, en contraste con el acopio tradicional de pergaminos individuales de los centros eclesiásticos. Así, se menciona como ejemplo el desplazamiento del cartulario de Manosque para la actividad jurídica del Hospital, Le Blévec y Venturini 1993.

6 Castro 1941 y Guijarro Santos 2009.

J. A. Fernández hizo una portada de presentación bajo el título: "Cartulario escrito en Vitela, que contiene diferentes privilegios reales, donaciones, concordias, y otras escrituras, desde el año 1117 hasta el de 1175 , con algunas otras que se le aumentaron después, y llegan al de 1198. Todas pertenecientes a los derechos que antes fueron de la orden y milicia de los Templarios y ahora la ínclita religión de San Juan de Jerusalén \&c».

8 Parece que uno de los más antiguos es el «Cartulario del Temple de Richerenches», encomienda del bajo Ródano, que se comenzó a realizar a partir del tercer cuarto del siglo XII, quizá poco antes que el de Novillas, Le Blévec y Venturini 1993: 452. Este Cartulario está publicado: Ripert-Monclar 1907.

9 Sans i Travé y Pladevall i Font 2006. 
julio de 1198. Ambos documentos contienen curiosamente sendas donaciones regias, de Alfonso I y de Sancho VII. ${ }^{10}$

La inserción de este último texto presenta unas características paleográficas muy distintas al documento que sigue, tal y como se puede apreciar a partir del cuerpo y trazado de las letras, más angulosas y pequeñas, así como en el cuerpo y caja de escritura de unas líneas muy cercanas unas de otras. Estas señales gráficas indican que, aunque el asunto de la donación del rey Sancho está en unidad topográfica con el orden del cuadernillo en el que se copia y que hace memoria de la actividad de la orden en torno a Cortes, Cabañas y Razazol entre 1139 y 1165 (docs. 122139), la transcripción relativa a 1198 se pudo agregar con posterioridad (vid. Cuadro de la estructura y contenidos del Códice). De hecho, esta data desentona con la secuencia cronológica del grueso de la documentación contenida en el códice, y que se cierra a mediados de los años sesenta para las posesiones navarras, en concreto en un texto de abril de 1166 concerniente a una entrega de bienes en Artieda, y algo más tarde, en 1189, para las posesiones aragonesas, dentro del actual término de Novillas. ${ }^{11}$

La letra gótica libraria, aunque disímil de la clásica morfología que presentan las obras eclesiásticas, predomina en toda la foliación. ${ }^{12}$ Igualmente se observan cambios de mano, a tenor de las variaciones en el tamaño de la caja de escritura, el estilo y colocación de las letras, unas veces más angulosas y otras más asentadas y redondas, con diferenciaciones del módulo y ángulo, así como el número de líneas dispuestas en cada pliego. Un ejemplo de ello se aprecia en los cuadernillos 23 y 24 , que presentan los listados de los cofrades del Temple con hasta tres modelos de escritura. También se singularizan los cuadernillos 13,14 y 15 , que se distinguen del conjunto no solo por la tipología de las letras sino también por no rubricar las iniciales de las copias y por repetir algunos de los textos, caso de la cesión de los derechos episcopales de la iglesia de Novillas (1135) o el acuerdo de los freires del Temple con los habitantes de Novillas y Cortes sobre el reparto de las aguas de la fuente de esta última localidad (1145). ${ }^{13}$ Estas duplicaciones documentales, tanto en extracto como en extenso, que también se aprecian en otros asientos del cartulario, son quizá indicadoras de que la concepción y elaboración del manuscrito estuvieron influidas por la intervención de fuentes de diversa procedencia y carácter heterogéneo, la mediación de varias manos y la existencia de distintos materiales diplomáticos, tanto originales como copias simples o noticias sueltas. ${ }^{14}$ Por otro lado, un análisis

10 AHN, L.595, f. 72v.-73r., n. 221: Alfonso I dona a Lope Garcés Peregrino la almunia de Añesa y AHN, L.595, f. 47 r., n. 140: Sancho el Fuerte dona al comendador templario de Novillas las tierras en Cortes, en Mora y en Novillas que explotaban tres exaricos moros.

11 AHN, Códices, L. 595, f. 151r., n. 385 (cuadernillo 7): María de Artieda se entrega al Temple con todos sus bienes en dicha localidad; $y$ AHN, Códices, L. 595, f. 7r., n. 24 (cuadernillo 1): donación de una pieza de tierra en Novillas al Temple, por parte de Pedro de Borja.

12 Sánchez y Domínguez 2000.

13 AHN, Códices, L. 595, f. 19v., n. 40, y f. 104r.-104v., n. 282 (1135, octubre 17) y AHN, Códices, L. 595, f. 81r.-82r., n. 244, y f. 99r.-100r., n. 274 (1145, noviembre 8).

14 Se repiten, entre otros, el acuerdo de Bernardo, obispo de Zaragoza, y el maestre del Temple, Pedro de Rovira, en relación a la percepción de los diezmos de las tierras de la orden de 1147 ( $\mathrm{AHN}$, comparativo del léxico, como se hizo en relación al romance aragonés para el "Cartulario del Temple de Huesca», podría arrojar también algún tipo de luz en cuanto al origen de sus fuentes y rasgos de su lengua, y, en suma, al lugar y momentos de sus fases de redacción. ${ }^{15}$

Como ocurre con otros cartularios medievales, no es posible atribuir una autoría o determinar con precisión quienes dirigieron e intervinieron en la redacción sistemática y en los posteriores añadidos de la composición textual. La posible presencia de Arnaldo de Torroja en tierras navarras, en el verano de 1173, a raíz de la entrega del castillo de Cintruénigo a la orden del Temple, siendo comendador de Novillas, Pedro Juan, que sucedió en sus funciones ese mismo año a Lope de Sada que se convertiría en preceptor de Alcanadre, ${ }^{16}$ aguas arriba del Ebro y en tierras de dominio castellano, pudo estar también en relación con las razones que indujeron a la realización de la recopilación manuscrita, que coincidió igualmente con los enfrentamientos castellanonavarros, reactivados en la década de los años sesenta y setenta del siglo XII. Aventurarse a citar a un escriba o equipo como responsables de las distintas fases de la elaboración del corpus diplomático, sería irreflexivo, sin tener evidencias o un serio contraste de datos, que tampoco existen. ${ }^{17}$ De lo que no cabe duda es que las fechas señaladas fueron cruciales para la organización de los templarios en este ámbito territorial, y la concepción y realización de este cartulario es una señal de que así fue.

Tras la ofensiva militar llevada a cabo por Sancho el Sabio sobre la Rioja y Castilla Vieja, entre 1162 y 1167, durante la minoridad de Alfonso VIII, que le proporcionó el control efectivo sobre una buena parte de la cuenca del Cidacos, el Oja, el bajo Tirón y la Bureba, el reino castellano preparó una respuesta armada que comenzó el verano de 1173 y culminó en agosto de 1176. Los contrataques de los ejércitos de Castilla llegaron incluso a Pamplona, y su soberano procedió a resucitar la alianza con Aragón mediante la firma de dos tratados sellados el 20 de marzo de 1179 en Cazola ${ }^{18}$. El navarro a pidió la paz un mes después, desencadenando los lógicos ajustes fronterizos a izquierda y derecha de la fértil cinta del valle medio del Ebro, términos de confluencia y fricción de dichos reinos desde los tiempos de la muerte del Batallador, ${ }^{19}$ pero al mismo tiempo con una sólida presencia templaria. ${ }^{20}$

Estos conflictos políticos coincidieron con los primeros años del gobierno de Arnaldo de Torroja como maestre

Códices, L. 595, f. 3r., n. 6; f. 26 v.-27 r., n. 71) o el suscrito entre el maestre del Temple en Aragón y el prior de la orden de San Juan en Aragón y Barcelona acerca de la explotación de los sotos de Navasa y Rabit por parte de las encomiendas de Novillas y de Mallén de 1149 (AHN, Códices, L. 595, f. 29v.-30r., n. 79; f. 194 v.-196 r., n. 441).

15 Laguna Campos 1999.

16 Alonso García 1957: 202-207.

17 Quizá Guillermo de Auvernia, capellán de Arnaldo de Torroja, y que figura suscribiendo dos importantes donaciones al Temple, una la del castillo de Cintruénigo, de 1173, y otra posterior del mes de febrero de 1175 , pudiera estar detrás de la coordinación de la iniciativa escrituraria e institucional. Guillermo fue capellán desde 1172, y tal y como señala A. Forey, entre las funciones iniciales de estos cargos estaba la de la redacción de la documentación magistral, para lo que se le supone conocimientos jurídicos, notariales y escriturarios, Forey 1973: 315.

18 Álvarez Borge 2008: 32-43.

19 Fortún Pérez de Ciriza 1998: 627-639.

20 García Larragueta 1981: 635-648. 
provincial del Temple, desde el otoño de 1166, y cuya presencia en Cintruénigo «in manum et in presentia fratris Arnaldi de Turrerrubea», ratificando la entrega del castillo a la orden en $1173,{ }^{21}$ pudo obedecer a esos recientes lustros de tensiones fronterizas. Destaca, por ejemplo, que este importante acto no se incluyera en el códice, lo que presupone, entre otras cosas, que por esas fechas o ya estaba en marcha la compilación de los títulos de propiedad o no tenía sentido que se incorporara. El maestre, conocedor de los conflictos habidos entre Sancho VI de Navarra y Alfonso VIII de Castilla, y probablemente de las intenciones del primero de integrar todas las piezas y agentes políticos, sociales, económicos e institucionales de su reino, debido a la problemática que se arrastraba a partir de la rehabilitación regia pamplonesa, pudo intervenir para preservar los intereses de los templarios. Dispuso así la elaboración de una memoria compilatoria, a partir de las piezas textuales conservadas en extenso o extractadas, y las tradiciones ágrafas, bajo el epígrafe «Hec est carta de memoria», que tuvieron que rehacerse o reconstruirse.

La entrega de Cintruénigo de 1173 expresó el interés del rey navarro por seguir vinculando al Temple y a sus caballeros en los cuadros de sus decisiones políticas, y más especialmente fronterizas, como ya había hecho su padre décadas antes. ${ }^{22}$ Sancho, en esta ocasión, no obstante, pudo concebir la idea - sobre todo tras la sentencia del conflicto por parte de los árbitros encabezados por Enrique II de Inglaterra y que dejaba en evidencia su derrota diplomática y territorial (1177, marzo)-, que para identificar y vertebrar a los termplarios dentro de su proyecto había que situar un centro de operaciones dentro de los límites de su «golpeada» soberanía. La donación de la villa de Aberin a la orden, en tierra Estella, que se data en octubre de 1177, "presentibus fratribusque Arnaldo, scilicet de Turre Rubea, magistro Yspanie, et Martino Sancii, comendatori de Alcanadre, et omnibus fratribis qui regulariter ibídem Deo seruuiunt", pudo formalizar esta inquietud regia, de acuerdo con los intereses de ambas partes, concentrando a partir de entonces las redes propiamente navarras sobre esta sede, al igual que lo haría también en Ribaforada. ${ }^{23}$ En 1184 figurará en la documentación un comendador en Navarra, Pedro López de Erice "freire de Temple, que es comendatoris de Nauarra», cuya presencia en 1179, actuando como receptor de unos bienes en Funes, le podría hacer acreedor de esas funciones ya desde esta fecha, aunque tampoco hay datos concluyentes al respecto. ${ }^{24}$

21 Donación del castillo de Cintruénigo a la orden del Temple, en presencia del maestre Arnaldo de Torroja, por parte de Pedro de Cintruénigo y su mujer María de Cortes, (AHN, Ordenes Militares, San Juan de Jerusalén, carp. 915, n. 1d. Copia simple, que se puede fechar a comienzos del siglo XIII; AHN, Códices, L. 649, f. 174-175, n. 188 y ACA RC, 310, f. 63v.; Pub. Remírez Vallejo, Tambo Moros y Martínez 2009: $n$. 1, 205-206; Madrid Medina 2012, tomo II, vol. 1: n. 188, 281-282, y Reg. Gutiérrez del Arroyo 1992, vol. 1: n. 1045.

22 García Larragueta 1981: 650.

23 AHN, Ordenes Militares, San Juan de Jerusalén, carp. 915, n. 2. Traslado autorizado del 27 de agosto, 1321 (Reg. Gutiérrez del Arroyo 1992: n. 1046). AGN, Códice 7, f. 147-148 (Pub. Alegría Suescun, Lopetegui Semperena y Pescador Medrano 1997: n. 68).

24 AHN, Ordenes Militares, San Juan de Jerusalén, carp. 938, n. 2 (Reg. Gutiérrez del Arroyo 1992: n. 4533) y AHN, Ordenes Militares, San Juan de Jerusalén, carp. 873, n. 16 (Reg. Gutiérrez del Arroyo 1992: n. 2454).
Pero lo que sí habría de valorarse es la reordenación en esos años del mapa administrativo templario peninsular, a partir no solo de la aparición de un maestre provincial en Castilla-León y en Portugal (1178), ${ }^{25}$ sino también de los cambios de irradiación dominical, que se datan por estos años en la encomienda de Huesca. ${ }^{26}$

\section{Historia y estructura}

Según se relata en la presentación del cartulario, el estado de conservación del manuscrito, como el del resto de los diplomas y libros, era deficiente en el último tercio del siglo XVI. Luis de Talavera (1570-1573), castellán de Amposta, ordenó en el Capítulo provincial de 1572 intervenir con el propósito de reorganizar el archivo de San Juan de los Panetes y proceder, entre otras cosas, según menciona J. A. Fernández, a la restauración del códice «para preservarlo de la polilla que empezaba ya a devorarlo». ${ }^{27}$ Poco se hizo al respecto en relación a los cartularios y libros de la Castellanía por parte de los reformadores del archivo, Juan Domínguez de Campillo, prior de San Juan de los Panetes, y el notario Juan de Griabales, quienes para el 31 de mayo de 1575 habían clasificado la documentación en legajos y elaborado un índice de trescientas páginas, según apuntan J. Delaville Le Roulx y Aurea L. Javierre. ${ }^{28}$ Tal y como señala esta última, «no se preocuparon de los Cartularios, limitándose a poner sobre sus cubiertas, Videatur que esta muy bueno o Videatur que importa mucho, figurando errores, incluso de un siglo, en las fechas que les asignaron ${ }^{29}$

El uso y la falta de una política estable para la conservación de sus fondos provocaron más intervenciones del capítulo provincial y el gobierno central de la orden, con el fin de ir dando una cobertura normativa al depósito de los diplomas, manuscritos y libros. Por ello, se requirieron los servicios de J. A. Fernández, notario del tribunal eclesiástico del obispado de Tudela y archivero general de la orden de Santiago, que entre 1793 y 1809, se consagró a realizar los inventarios de los títulos, privilegios y asuntos de los fondos del archivo, formando quince inventarios, uno de bulas, un resumen de las actas de la Asamblea, además de identificar e indexar una gran parte de sus códices, y algunos libros.

Su tarea, que sería continuada por otros personajes, como el oficial del Ministerio de la Marina, Martín Rodón y Simón, tras la retirada de las tropas francesas (1827), sería fundamental para la historia de esta unidad archivística. Esta labor de catalogación y descripción de los fondos sanjuanistas y templarios ha trascendido hasta la actualidad por el rigor y claridad de sus inventarios, debido a sus dotes de sistematización, a sus conocimientos paleográficos y diplomatistas, así como a su experiencia archivística previa, prestada a la catedral de Tudela (post. 1773), a la orden

25 Los conflictos fronterizos y la reafirmación de la monarquía castellana, a partir del arbitraje inglés, pudo suponer una reordenación de las demarcaciones templarias hispanas (Martínez Díez 1993: 62-63).

26 Ledesma Rubio 1982: 140-153 y Gargallo Moya, Iranzo Muñío y Sánchez Usón 1981: 3-13.

27 AHN, Códice L.595, introducción, p. 2.

28 Delaville Le Roulx 1893: 9 y Javierre Mur 1947-1948: 161.

29 Javierre Mur 1947-1948: 161. 
de San Juan en Navarra (c.1785), a la de Santiago en Uclés (1789-1793) y al marqués de San Adrián (1793). ${ }^{30}$

Según indican J. Delaville Le Roulx y Aurea L. Javierre, también estuvieron depositados en la sede de San Juan de los Panetes otros cinco cartularios de la extinta orden templaria y un libro con la relación de cofrades en los dominios de España que son los actuales Códices de la sección del Temple del AHN clasificados en: L. 594, L.597, L.598, L.660, L.661, L.663 y por último el L.665, que recoge el citado registro de los caballeros cofrades. Todos ellos, datados entre el siglo XII y XIV, pasaron por las manos del librero, dotando a algunos de una portadilla de presentación, en concreto el L.594, 660 y $661,{ }^{31}$ y a otros de unas breves páginas de presentación, donde refería detalles de su contenido, cronología, número de textos, caso del L.597, L.598, L.663, L.665 ${ }^{32}$ y, por supuesto el L.595, objeto de la presente investigación, al que añadió un índice toponímico por documentos, como al L.598.

Es difícil certificar si la encuadernación final del cartulario L.595, como la del resto de los manuscritos, fue llevada a cabo personalmente o bajo la supervisión del archivero J. A. Fernández, o si una parte de la misma ya estaba hecha cuando lo revisó, ya que el orden y lógica de la encuadernación desaparece en varios momentos por la interpolación de algunos pliegos. Así, la inserción de los cuadernillos 13, 14 y 15 rompe la unidad inicial de contenidos, al igual que el cuadernillo 18. De la misma forma, los cuadernillos 3 y 4 se supone que debían tener continuidad en el número 19, y el marcado en el cuadro final como número 9 debía seguir al 7 . No cabe duda que J. A. Fernández conocía las alteraciones internas de la pieza codicológica, ya que son sus anotaciones manuales las que ayudan a seguir los saltos de páginas y la notación

\section{Guijarro Santos 2007}

31 Cartulario escrito en Vitela que contiene ciento once escrituras, desde el año de 1184, hasta el de 1283 correspondientes a la encomienda de Castellot (L.594, del siglo XIII y publicado por Torre Gonzalo, S. de la (ed.). 2009. El Cartulario de la Encomienda Templaria de Castellote (Teruel), 1184-1283. Zaragoza: Universidad de Zaragoza; Cartulario que contiene diferentes cartas de poblaciones, y fueros de lugares pertenecientes antiguamente a la Milicia del Temple y ahora a la Sagrada Religión de San Juan de Jerusalén hoy de Malta (L.660, del siglo XIV): Cartulario que contiene diferentes cartas de poblaciones y fueros de lugares pertenecientes antiguamente a la Milicia del Temple y ahora a la Sagrada Religión de San Juan de Jerusalén, hoy de Malta (L.661, f. s. XIV-co. XV). Describe los cartularios Javierre Mur 1947-1948: 184-187.

32 Cartulario escrito en Vitela que contiene diferentes Bulas Apostólicas y Privilegios Reales \&c. Donaciones y otros Documentos pertenecientes a las Encomiendas, bienes, y derechos que fueron del Orden y Milicia del Temple, y hoy corresponden a la Inclita y Sagrada Religion del Hospital de S. Juan de Jerusalén (L.597, finales S. XIII); Cartulario escrito en Vitela que contiene doscientas diez y siete Escrituras de Privilegios, Donaciones y otros Documentos pertenecientes a la Encomienda IIamada, o intitulada del Temple de Huesca, Desde el año de 1148, hasta el de 1273 en cuyo tiempo parece se escribió (L.663, del siglo XIII); este último está publicado, con el complemento de una serie de documentos de la Lengua de Aragón del AHN: Cartulario del Temple de Huesca. 1985. Gargallo Moya, A., Iranzo Muñio, M. a T. y Sánchez Uson M. a J. (eds. e índices), Zaragoza: Anubar; pero no contiene introducción crítica. E códice L.598 (s. XIII), que incluye un índice alfabético de pueblos, tiene el mismo título que el L.597. Por último, el ya mencionado anteriormente: Hermandad o Cofradía de la Orden, y Milicia de caballeros del Templo de Salomón de Jerusalén en los dominios de España (L. 665, del siglo XII). Describe estos códices Javierre Mur 1947-1948: 166-168, 178-180 y 187-188. documental de los cuatrocientos cuarenta y cuatro textos es correlativa, a pesar de la encuadernación anómala.

De entre todos los códices del Temple de los fondos de la Castellanía de Amposta de Zaragoza y ahora en el AHN, sobresale por su antigüedad y la riqueza de información el L.595, así como el L. 665 que contiene una interesante relación de cofrades de la orden en Aragón, Pamplona y Castilla. Dado que en esta ocasión se estudia el primero de ellos, procede destacar la calidad de sus copias y la unidad formal, a pesar de la intervención de distintas manos en su factura escrituraria. En segundo lugar, cabe señalar el elevado y significativo número de documentos que copia y extracta, y que supone la priorización de la sede de Novillas en el cuadro de organización espacial de la orden templaria en el siglo XII, pero también en la frontera de los reinos de Aragón y Pamplona-Navarra. Y, en última instancia, por sus aportaciones concernientes a las estructuras sociales y económicas de la nueva realidad territorial de estos reinos, construida a partir de la recuperación ante el Islam del espacio que abarca desde las riberas del Ebro en Zaragoza hasta el río Ega, aguas arriba, con las áreas de influencia en torno a esta cinta fluvial.

\section{EL CORPUS DOCUMENTAL}

El corpus documental del cartulario del Temple en Novillas está compuesto por cuatrocientos cuarenta y cuatro documentos de distinta naturaleza y tipología en relación a la formación y gestión patrimonial de esta encomienda en el siglo XII. ${ }^{33} \mathrm{El}$ códice, por tanto, no incluye piezas diplomáticas de esta sede en calidad de célula administrativa incardinada en la organización institucional y gubernativa internacional de la orden; como tampoco figuran copias de bulas pontificales. Esta ausencia de textos relativos a los principales centros de poder que vestían de legitimidad a las realidades regionales, siquiera durante su primera andadura, como la sede central magistral y el papado, implica que el conjunto escrito fue constituido, en principio, con una finalidad de aplicación provincial sobre el ámbito hispánico, en la que también tuvo cabida la afirmación de derechos dentro de la organización eclesiástica.

El análisis de los documentos indica el origen y las distintas etapas de la constitución del patrimonio templario de la encomienda de Novillas (1117-1198), a partir de la variada tipología textual que describe las formas de adquisición, gestión y explotación de los bienes: los privilegios reales, los acuerdos con la iglesia de Tarazona, Zaragoza y Calahorra en relación a derechos episcopales y otros asuntos, las entregas de la alta nobleza participante en la Reconquista como las de parte de la familia de Raimundo de Cortes, su esposa Urraca y su progenie, otras donaciones de vecinos de la villa de Novillas, las compraventas y los cambios, así como

33 Realizó su catalogación en 1954, en calidad de ayudante de la Cátedra de Historia Medieval de España de la Universidad de Zaragoza (1949-1954) y bajo la dirección de José M.a Lacarra, María González Miranda, que llegaría a ser directora del Archivo Histórico Provincial de Zaragoza: González Miranda, M. 1954. Cartulario del Temple Códice № 691 del Archivo Histórico Nacional. Catálogo, Zaragoza: Texto mecanografiado. Este ejemplar se conserva en la Biblioteca Nacional de Madrid. Agradezco los datos personales facilitados por Reyes Serrano González, hija de M. González, y actual archivera de las Cortes de Aragón. 
las entregas a censo. Abarcan una amplia y rica diversidad de bienes y propiedades, que incluyeron las actuaciones en relación a las piezas de tierra y heredades, solares, viñas, molinos, casas y casales, disfrute de aguas, huertos, pozos, sotos para el ganado, bosques y otros derechos.

Los diplomas e instrumentos muestran el diseño de una estructura dominical extensa y compleja, así como las fases y formas de adquisición de los bienes. A. I. Lapeña, que estudió las tipologías y categorías documentales, reflejó en una serie de mapas y gráficos esta realidad, resaltando, entre otras cosas que la conformación del cuadro de las propiedades se hizo en la primera mitad del siglo XII o que los modelos de explotación fueron variados y acondicionados a las realidades poblacionales y territoriales. ${ }^{34}$ Las donaciones reales iniciales, por ejemplo, procuraron la entrega de villas, como la propia Novillas (1135), Razazol (1138), Ambel, Alberite y Cabañas (1151), para garantizar el control de territorios estratégicos y de contacto con los reinos vecinos, como se analizará a continuación. Asimismo, la presencia templaria provocó otro tipo de protección, orientada a dar la cobertura necesaria para el desarrollo de la institución mediante distintos privilegios y exenciones. En esta línea, García Ramírez concedió a los habitantes de Villavieja, de Puente la Reina, la dispensa del pago de caloñas por la posesión de heredades fuera de sus términos (1146) o la exención del pago de peaje y lezda a la orden en todo el reino navarro (1149). ${ }^{35}$

Otras de las prerrogativas del Temple tuvieron su origen en las concesiones episcopales procedentes de la sede zaragozana, turiasonense y pamplonesa, si bien la complejidad de los asuntos en relación a la percepción de unos derechos tradicionalmente eclesiásticos, daría lugar a largos procesos de litigio. La iglesia de Novillas (1135 y 1137), las de Ribaforada y Ambel (1145 y 1148), así como Añesa (1149) fueron objeto de choque y reajuste en relación a la percepción de diezmos y cuartas episcopales. ${ }^{36}$ También habría directrices más generales, como por ejemplo la suscrita en relación al modelo de recaudación de los diezmos de las tierras de la orden (1147, julio 15), que denota el interés por el control de unas copiosas rentas generadas por los grupos de población dependiente. ${ }^{37}$

La adquisición de los principales recursos patrimoniales se nutrió fundamentalmente de donaciones particulares, a partir de las cuales se obtuvieron todo tipo de bienes rústicos, derechos territoriales y disfrute de recursos que dieron forma al paisaje dominical, completado por una inteligente política

\footnotetext{
34 Lapeña Paúl 1978b: 113 y 122 (mapas); 118, 120, 121, 124 (gráficos).

35 AHN, Códices, L. 595, f. 163 v., n. 417 y AHN, Códices, L. 595, f. 28 r., n. 74; AHN, Ordenes Militares, San Juan de Jerusalén, caja 8488, n. 2 (Pub. De Albon 1913: n. 546, 334, y Reg. Gutiérrez del Arroyo 1992: n. 4).

36 AHN, Códices, L. 595, f. 19 v., n. 40, y f. 104 r.-104 v., n. 282 (Pub. De Albon 1913: n. 94, 70). AHN, Códices, L. 595, f. 104 v.-105 r., n. 283 (Pub. De Albon 1913: n. 143, 100). AHN, Códices, L. 595, f. 111-112, n. 291 (Pub. Lacarra 1952: n. 358, 578). AHN, Códices, L. 595, f. 136 v.-137 r., n. 341 y AHN, Ordenes Militares, San Juan de Jerusalén, carp. 628, n. 5 (Pub. Lacarra 1952: n. 367, 586-587). AHN, Códices, L. 595, f. 28 v., n. 75.

37 Este acuerdo se suscribe entre el obispo de Zaragoza, Bernardo, y el maestre del Temple, Pedro de la Roera, determinándose que en las tierras de la reserva los diezmos se dividirán por la mitad, y en las tierras cultivadas por exaricos los pagarán íntegros. AHN, Códices, L. 595, f. 3 r., n. 6; f. 26 v.-27 r., n. 71 (Pub. De Albon 1913: n. 460, p. 285).
}

de compraventas y permutas, especialmente intensa en la década de los años cuarenta y cincuenta. ${ }^{38}$ Las propiedades fueron objeto de un plan de explotación directa e indirecta, a partir de contratos censales a particulares y poblaciones (Novillas o Razazol) para la generación de excedentes en tiempos de expansión. La descripción de este mapa funcional socioeconómico, su ámbito de irradiación y su impronta será tratada con detalle en la monografía en curso anteriormente referida. ${ }^{39}$

Tal y como ya se ha adelantado, la complejidad de las circunstancias políticas hispanas tras la muerte de Alfonso I (1134, septiembre), situada en las mismas coordenadas temporales de la llegada de la orden del Temple a la Península Ibérica dentro de un nuevo marco de expansión de la Cristiandad, así como la necesidad de fijar los espacios y redes de poblamiento cristiano en las tierras recuperadas dotaron a la encomienda de Novillas hasta el último tercio del siglo XII de una especial significación, como refleja el análisis de sus piezas diplomáticas. ${ }^{40} \mathrm{El}$ área del margen derecho del Ebro que delimitan la cuenca del río Queiles y Huecha, que engloba desde las vertientes septentrionales del Moncayo, Ágreda, Tulebras, Tudela y los territorios Tarazona y Campo de Borja hasta Novillas y el río Arba, se convirtió en una plataforma de contacto y de enfrentamiento político entre los reinos de Aragón, Castilla y el de Pamplona, restaurado este último al margen de la voluntad del Batallador por García Ramírez, uno de sus más cercanos colaboradores militares, y «tenente» desde 1133 de la plaza de Tudela. ${ }^{41}$

Una buena parte de los diplomas del cartulario de Novillas trasciende los movimientos de la monarquía en este segmento fronterizo, donde también entraron en liza personajes secundarios, los milites y seniores de un dominio y otro, bajo patrocinio regio y al compás de las directrices de sus señores naturales. La institución del Temple, al igual que la orden del Cister entre la desembocadura del río Alhama y Aragón, con sus sedes de Fitero y la Oliva, ${ }^{42}$ se convirtió en un importante actor dentro de esa contienda sobre este feraz tramo del Ebro, siendo un mediador o incluso un instrumento de los intereses creados en ese ámbito de tensión territorial política y dominical. La tipificación documental, un recurso clásico para la descripción de este tipo de repertorios, cabría equipararse a una mera orientación formal de análisis, ya que la identidad del manuscrito no habría de ser definida solo a partir de la cuantía o calidad de las dádivas monárquicas o señoriales, como tampoco por la autenticidad o veracidad de unos actos jurídicos que de otra forma no serían conocidos al verse perdidos sus originales. ${ }^{43}$

La memoria histórica del cartulario refrenda no solo las estrategias de expansión patrimonial de la institución del Temple, sino que refleja de manera simbólica las facetas

38 Lapeña Paúl 1978b: 114-124.

39 Vid. nota 2.

40 Lapeña Paúl 1978a y 1978b.

41 Lacarra 1947-1948: n. 169: Garçia Remireçin Calataiub et in Tutela et in Montson; Ubieto Arteta 1973: 223.

42 Pavón Benito 2005.

43 Sánchez Mairena (2012: 218) llega a afirmar que los testimonios de algunos cartularios se han elevado al rango de reliquias, como un talismán casi sacral. 
funcionales de la orden sobre un espacio concreto, los rebordes meridionales del reino de Aragón y Navarra, y sobre una secuencia temporal fundamental del siglo XII para el proceso de reconquista y consolidación de los reinos hispanos, y que englobó desde la década de los años veinte hasta la de los setenta de dicha centuria. La clave para comprender unitariamente este cartulario está en estrecha relación, igualmente, con los autores intelectuales, a cuya cabeza estuvo el maestre Arnaldo de Torroja. Éstos supieron leer la oportunidad de realizar este compendio, con la finalidad de consolidar el área de influencia territorial y los derechos jurisdiccionales de una encomienda, con una especial potencialidad agraria y protegida por poderes locales, justo en un tiempo de graves dificultades fronterizas contrapesadas, por otro lado, con el afianzamiento del asentamiento templario en el marco peninsular. ${ }^{44}$

Son muchos los ejemplos que acreditan estas cuestiones, y que profundizan al detalle de toda esta compleja realidad a partir del cuerpo textual compuesto por documentos copiados, reconstruidos o extractados en una memoria conjunta. Así, se pueden subrayar, en primer término, las pugnas regias iniciales que tuvieron lugar en la secuencia cronológica que abarca entre 1135 y 1148, centralizadas en torno a Novillas, y Razazol, una almunia próxima a la anterior, ambas hoy en la divisoria aragonesa. En 1135 García Ramírez otorgaba la villa y el castillo de Novillas a templarios y hospitalarios, y dos años después la de Razazol a Raimundo de Cortes y su hermano Conan, ${ }^{45}$ hermanos a su vez de Rotrou IV de Perche (1100-1144) - primos de Alfonso el Batallador-, y con sólidos vínculos con el Temple en vida y a través de la siguiente generación, en la persona de María, hija del mencionado Raimundo, y miembros de su cofradía. ${ }^{46}$

Ramón Berenguer IV, respondió a la afrenta del pamplonés en 1138 (abril, 27), donando a la orden del Temple la villa de Razazol con todos sus términos, ${ }^{47}$ en una operación en la que aparece involucrado Calvet, ${ }^{48}$ señor

44 Vid. nota 24. Por otro lado, la simbología identitaria de un cartulario fue compartida por otros cartularios o depósitos archivísticos de las órdenes militares, en especial el del monasterio hospitalario de Sigena, como guardián de la memoria de una dinastía, Bonet Donato 2014: 74-77.

45 AHN, Ordenes Militares, San Juan de Jerusalén, carp. 670, n. 2 (Pub. De Albon 1913: n. 100, p. 73). El extracto documental del cartulario que recoge la donación a templarios de la villa Novillas por parte de García Ramírez, fragmento con una letra del siglo XVIII, y en estrecha relación con el diploma de la entrega que incluye también el castillo y que tiene como beneficiario además al Hospital, es un texto (AHN, Códices, L. 595, f. 18v., n. 39), copiado a continuación de la transcripción del testamento de Alfonso I, y dentro de una sección del cartulario que agrupa tres cuadernillos con textos relativos al patrimonio exclusivo de la mencionada villa (cuadernillos n. 3, 4 y 19). La donación de Razazol a Raimundo y su hermano Conan (AHN, Códices, L. 595, f. 10r., n. 27).

46 Remírez Vallejo 2009 y 2016: 126-165.

47 AHN, Códices, L. 595, f. 9r., n. 25; Pub. De Albon 1913: n. 154, 107-108.

48 No es fácil precisar quien fue Calvet, nominación que designa a distintos individuos en la documentación de la época durante tres generaciones, y que, por otro lado proporcionaría pistas acerca del origen de su relación con el Temple. Por la cronología podría tratarse de Calvet de Belorado, que aparece como tenente de Belorado en 1121 y suscribiendo, sin mención locativa, sendas donaciones a García, señor de Belorado, en 1129 (Lacarra 1947-1948: n. 159 y 160 y Lema Pueyo 1990: n. 215 y 217). del lugar desde octubre de 1134 por voluntad de Ramiro II. ${ }^{49}$ Esto supone que dichos emplazamientos estuvieron directamente afectados por el conflicto, y que la iniciativa del rey pamplonés pudo obedecer, en sus primeros compases, al aparente clima de pacificación con Castilla, tras prestar vasallaje a Alfonso VI el mes de mayo de 1135 en Nájera. La entrega de Razazol vino a ratificar las conquistas navarras realizadas en la primavera de 1137 ante Aragón, tras su alianza con Alfonso Enríquez, conde de Portugal. ${ }^{50}$ Del mismo modo, se entiende la entrega a la orden por parte de García Ramírez del término repoblado, ya desde tiempos de Alfonso I, ${ }^{51}$ de Los Arcos (1148), superponiéndose aquí sobre la política de fijación del poblamiento de la antigua sede de Curnonium, el interés por consolidar un espacio próximo a los intereses castellanos. ${ }^{52}$

Los donativos regios figuran aquí en un cuadro de afirmación soberana, dentro de una tendencia, que en el plano feudal, estaba sucediendo en algunos territorios catalanes en tiempos de Ramón Berenguer IV y Alfonso II, como explicó en su día M. Bonet. Las entregas regias se entendían así como directrices que poco tenían que ver con los procesos reconquistadores o de control de vías arteriales de comunicación a través de recintos fortificados o puntos estratégicos, en los que también la monarquía aragonesa contó con el Hospital y el Temple..$^{53}$

Aunque destacan formalmente los documentos regios, a los que los copistas dotaron de unos rasgos distintivos reproduciendo los crismones iniciales, las suscripciones regias y notariales, así como otras figuraciones plásticas, no cabe menoscabar la singularidad de las actuaciones protagonizadas por las estirpes locales de ascendencia señorial, referentes imprescindibles para conferir un valor añadido a la orden sobre su entorno y dentro del concierto de los poderes soberanos. La familia de Raimundo de Cortes y su mujer Urraca, cuya hija María perpetuó la filiación con la orden en consonancia con su esposo Pedro de Cintruénigo, encarnó ese arraigo y apoyo social por parte de unos ascendentes linajes aristocráticos, tanto al Temple como a la monarquía pamplonesa. ${ }^{54}$ Mientras que las circunstancias influyeron para que algunos personajes del círculo regio, como el conde Ladrón o Rodrigo de Azagra cambiaran de señor natural, pasándose a Castilla, los de Cortes y los Lehet mantuvieron su fidelidad, incluso en los momentos más acuciantes para su señor natural. ${ }^{55}$ Llama la atención, no obstante, que todos ellos formaran parte de la cofradía de esta institución militar ya constituida para 1141,

49 La donación de Ramiro II a Calvet y la posterior entrega de este al Temple se integran en un solo documento, siendo imposible determinar en qué momento la villa recayó en manos de la orden (AHN, Códices, L. 595, f. 9r.-v., n. 26), pues la data de octubre de 1134 quizá corresponde a la donación real.

50 Fortún Pérez de Ciriza 1998: 611-616.

51 Lema Pueyo 1990: n. 58: Alfonso I realiza una donación al abad de Leire en abril de 1113, estando en "Cornonia de illos Archos», lo que podría hacer suponer que el monarca, presente en el viejo emplazamiento de origen romano estuviera articulando un nuevo diseño poblacional del núcleo nuevo, que décadas después recibiría un fuero, por parte de Sancho VI, en 1176, Fortún Pérez de Ciriza 1982: n. 25.

52 AHN, Códices, L.595, f. 27, n. 73. El cartulario incluye una nueva copia del texto en el f. 160v., n. 406.

53 Bonet 2007.

54 Vid. nota 38.

55 Martín Duque 2000: 6-8 y Fortún Pérez de Ciriza 2000. 
que presidía el rey y el obispo de Pamplona, confirmando la idea de que García Ramírez se valió de la orden para cohesionar y consolidar su proyecto político. ${ }^{56}$ Estas y otras cuestiones relativas al trasfondo político, económico, social y confraternal están siendo analizadas en el estudio y edición documental ya referidos, que detallará, a partir de estas y otras evidencias, las características y fórmulas de implantación y desarrollo de la institución de los templarios, además de las consecuencias de su irradiación regional. ${ }^{57}$

\section{REFLEXIONES FINALES}

La primera etapa de la andadura y asentamiento del Temple en el valle medio del Ebro, y más sobre el espacio occidental de la vieja taifa zaragozana, tuvo una serie de hitos singulares, que elevaron a la sede de Novillas, a ser algo más que un mero foco de organización de una institución consagrada a la guerra contra el Islam, con el apoyo de un sólido patrimonio beneficial, entre el área de los ríos Queiles y el Arba. El cartulario que hoy se conserva en el AHN (L.595) así lo ratifica, a través de la documentación que copió, memoria viva de las posesiones y dominios templarios sobre un complejo radio de acción territorial.

La villa y encomienda de Novillas estaba situada en la confluencia de las fronteras entre la monarquía castellana, la aragonesa y la pamplonesa que, a partir de 1134 y durante todo el siglo XII, dirigieron una gran parte de sus esfuerzos políticos y militares a consolidar sus límites mediante actuaciones diferentes y complejas en el tiempo y sobre la cinta media del Ebro. Ya fuera debido a unas razones $u$ otras, las tres soberanías jugaron sus bazas y opciones en ambiciosas campañas o negociaciones diplomáticas, triangulando complejos intereses y modos de organización territoriales, capitaneados preferentemente por Castilla. Estas directrices y acciones de la alta política, que desacreditaron y dejaron en una posición de inferioridad a Navarra sobre el tablero peninsular, a partir de los tratados de Vadoluengo (1135), Carrión (1140) Lérida (1157) o Cazola (1179), tuvieron su lógica réplica a pequeña escala alrededor de Novillas; y la orden del Temple fue una importante pieza en esas actuaciones y fluctuaciones monárquicas de dominio geográfico.

Esta zona de confluencia, según desvela la documentación del cartulario estudiado, fue también especialmente atrayente, teniendo en cuenta las características del valle medio del Ebro, con una retícula poblacional concentrada sobre los cursos fluviales y sus vegas, compuesta inicialmente por núcleos pequeños y medianos de origen y tradición musulmana, enclaves que se convirtieron en receptores inicialmente de contingentes humanos de procedencia ultrapirenaica, según desvela la onomástica de los textos del códice, y que será objeto de estudio en una próxima ocasión.

En suma, los actos diplomáticos copiados y extractados en el cartulario de Novillas representan, aparentemente, la

56 Ubieto Arteta 1980, Texto A: asientos 1-3 y 20-22 (el obispo de Pamplona, Sancho Larrosa; el conde Ladrón y su esposa); asiento 40 (el rey García), asiento 43 (Martín de Lehet), asiento 49 (Martín López de Estella), asiento 60 (Rodrigo de Azagra).

57 Vid. nota 2. temprana concreción escrita del conjunto de la memoria institucional del Temple a escala regional, con la intención de fijar un registro de las pertenencias y participaciones beneficiales de este centro comendaticio, desde sus orígenes hasta el último tercio del siglo XII. Desde la orden, y posiblemente debido a la iniciativa de Arnaldo de Torroja, se ideó reunir sobre un instrumento figurativo toda aquella pluralidad de información que justificase jurídicamente la sanción de sus posesiones y derechos, recibidos o adquiridos.

El manuscrito, no obstante, representa algo más que un instrumento del control dominical interno templario, tanto por sus contenidos como por su lógica constructiva y comunicativa, pues desvela una realidad y una identidad corporativa que va más allá de una definición de un patrimonio. Por ello, y a partir del momento de su redacción fue adquiriendo, además de la categoría de recurso útil para garantizar la correcta administración de un patrimonio y gestión de unos derechos, la impronta inconsciente de recurso para conocer y valorar una serie de actuaciones políticas monárquicas, y por extenso de la nobleza y de la población locales, en un momento crucial de la constitución y articulación de los espacios de las monarquías hispánicas durante una buena parte del siglo XII; soberanías que además de sobre otros agentes, se apoyaron en la orden del Temple para definir sus fronteras.

\section{CUADRO DE LA ESTRUCTURA Y CONTENIDOS DEL CÓdICE L. 595 CARTULARIO DE LA ENCOMIENDA TEMPLARIA DE NOVILLAS} (ÚLTIMO CUARTO S. XII)

\begin{tabular}{|c|c|c|c|}
\hline 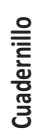 & Foliación & 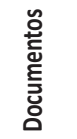 & Características formales \\
\hline 1 & $\begin{array}{l}\text { f. 1r.-8r. (7v.-8v. en blanco) } \\
\text { Documentación relativa a } \\
\text { Razazol, Gallur, Boquiñeni, } \\
\text { Mallén y Cabañas. }\end{array}$ & $1-24$ & $\begin{array}{c}\text { Gótica libraría } 1 \text { y gótica } \\
\text { documental } \\
\text { La documentación se inicia } \\
\text { con inicial rubricada. } \\
\text { Se copia un documento de } \\
\text { Alfonso I con crismón inicial } \\
\text { y suscripción real (n.1) y otro } \\
\text { de Ramiro II (n.2). } \\
\text { Se reproducen signos } \\
\text { notariales y otras } \\
\text { suscripciones. }\end{array}$ \\
\hline 2 & $\begin{array}{l}\text { f. 9-16 (14v-16v. en blanco) } \\
\text { f. 9. Incipit liber de } \\
\text { hereditates que habent } \\
\text { illos fratres in Raçaçol et } \\
\text { comparas uel donatiuum } \\
\text { que ad illos fecerunt et } \\
\text { comes Barchinnonia et rex } \\
\text { Ranimirus } \\
\text { f. 16v. Incipit itaque de illas } \\
\text { hereditates de Ambel }\end{array}$ & $24-37$ & $\begin{array}{c}\text { Gótica libraría } 1 \\
\text { Se copian Crismones iniciales } \\
\text { y suscripciones reales. } \\
\text { La documentación se inicia } \\
\text { con inicial rubricada }\end{array}$ \\
\hline 3 & $\begin{array}{c}\text { f. } 17 \mathrm{r} .-23 \mathrm{v} . \\
\text { f.17r. Incipit liber de } \\
\text { testamento que fecit rex } \\
\text { Illefonsus et de destinamento } \\
\text { similiter, et de hereditatres et } \\
\text { laxaset comparationes que } \\
\text { sunt factas in Nouellas uel in } \\
\text { pertienciis suis }\end{array}$ & $38-57$ & $\begin{array}{l}\text { Gótica libraría } 1 \\
\text { La documentación se inicia } \\
\text { con inicial rubricada. }\end{array}$ \\
\hline
\end{tabular}




\begin{tabular}{|c|c|c|c|}
\hline 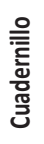 & Foliación & 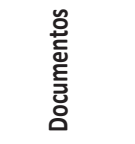 & Características formales \\
\hline 4 & $\begin{array}{c}\text { f.24r.-33v. } \\
\text { Tras este cuadernillo, el } \\
\text { orden documental supone } \\
\text { que seguía con el cuadernillo } \\
19 \\
\text { Nota marginal: sigue } n \text { ㅇ 353, } \\
f .137\end{array}$ & $\begin{array}{l}\text { 57-93 } \\
\text { (documento } \\
\text { que sigue } \\
\text { en el } \\
\text { cuadernillo } \\
\text { 19, f. } 137 \text { r.) }\end{array}$ & $\begin{array}{l}\text { Gótica libraría } 1 \\
\text { La documentación se inicia } \\
\text { con inicial rubricada. }\end{array}$ \\
\hline 5 & $\begin{array}{l}\text { f.34r.-40v. } \\
\text { El f. 34r. contiene el final del } \\
\text { documento } 365 \\
\text { El f. 34v. (doc. 94) sigue en el } \\
\text { f. } 143 r \text {., en el cuadernillo } 19 . \\
\text { Este cuadernillo se supone } \\
\text { seguía al no } 19 .\end{array}$ & $94-121$ & $\begin{array}{c}\text { Gótica libraría } 1 \\
\text { La documentación se inicia } \\
\text { con inicial rubricada. } \\
\text { Se copian las suscripciones } \\
\text { notariales. }\end{array}$ \\
\hline 6 & $\begin{array}{c}\text { f. } 41 r .-48 v . \\
\text { (f. } 44 v ., 47 v \text { y } 48 \text { r. y v. en } \\
\text { blanco) }\end{array}$ & $122-140$ & $\begin{array}{c}\text { Gótica libraría } 1 \\
\text { Se copian Crismones } \\
\text { iniciales, suscripciones reales } \\
\text { y signos notariales. } \\
\text { La documentación se inicia } \\
\text { con inicial rubricada. }\end{array}$ \\
\hline 7 & $\begin{array}{c}\text { f. } 49 \mathrm{r} .-55 \mathrm{v} \text {. } \\
\text { El f. } 49 \mathrm{r} \text {. recoge el final del } \\
\text { documento } 219 \text { (f.71v. del } \\
\text { cuadernillo 9) } \\
\text { Se supone que este } \\
\text { cuadernillo podía seguir } \\
\text { al no } 9 .\end{array}$ & $\begin{array}{l}\text { 141-163 } \\
\text { Final del } \\
\text { documento } \\
219\end{array}$ & $\begin{array}{c}\text { Gótica libraría } 1 \\
\text { Se copian signos notariales. } \\
\text { La documentación se inicia } \\
\text { con inicial rubricada. } \\
\text { Los documentos 161-163 } \\
\text { son en gótica libraría más } \\
\text { rotunda }\end{array}$ \\
\hline 8 & f. $56 r .-63 v$. & $164-194$ & $\begin{array}{l}\text { Gótica libraría } 1 \\
\text { Se copian signos notariales. } \\
\text { La documentación se inicia } \\
\text { con inicial rubricada. }\end{array}$ \\
\hline 9 & $\begin{array}{c}\text { f.64r.-71v. } \\
\text { El final del documento } 219 \\
\text { del f. 71v. está en el f. 49r. del } \\
\text { cuadernillo } 7 .\end{array}$ & $194-219$ & $\begin{array}{c}\text { Gótica libraría } 1 \\
\text { Se copian Crismones iniciales } \\
\text { y suscripciones reales. } \\
\text { La documentación se inicia } \\
\text { con inicial rubricada }\end{array}$ \\
\hline 10 & $\begin{array}{l}\text { 72r.-79v. } \\
\text { f. 73v., en letra gótica: } \\
\text { De illos populatores de } \\
\text { Nouellas de illo cannocar, ad } \\
\text { undécima parte fructus sicut } \\
\text { populati de reddant integro } \\
\text { ad fratribus }\end{array}$ & $220-237$ & $\begin{array}{l}\text { Gótica libraría (cuatro tipos } \\
\text { gráficos) y gótica documental } \\
\text { Se copian Crismones } \\
\text { iniciales, suscripciones reales } \\
\text { signos notariales. } \\
\text { La documentación se inicia } \\
\text { con inicial rubricada }\end{array}$ \\
\hline 11 & f. $80 \mathrm{r} .-87 \mathrm{v}$. & $238-252$ & $\begin{array}{c}\text { Gótica libraría } 1 \\
\text { Se copian Crismones } \\
\text { iniciales, suscripciones reales } \\
\text { signos notariales. } \\
\text { La documentación se inicia } \\
\text { con inicial rubricada. } \\
\text { Escritura de distintos } \\
\text { escribanos. }\end{array}$ \\
\hline 12 & $\begin{array}{c}\text { f.88r.-92v. } \\
\text { Falta una hoja para } \\
\text { completar el cuadernillo de } \\
\text { seis hojas, cortada entre el f. } \\
\text { 92v. y } 93 \text { r. }\end{array}$ & $253-265$ & $\begin{array}{c}\text { Gótica libraría } 1 \\
\text { Se copian Crismones } \\
\text { iniciales, suscripciones reales } \\
\text { signos notariales. } \\
\text { La documentación se inicia } \\
\text { con inicial rubricada. }\end{array}$ \\
\hline
\end{tabular}

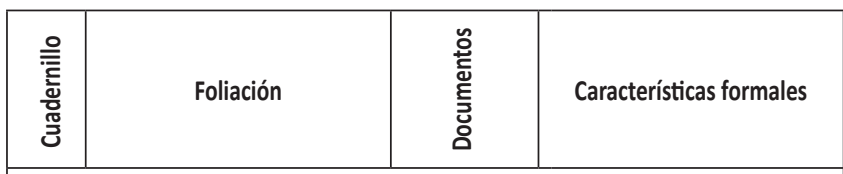

INSERCIÓN DE LOS CUADERNILLOS 13, 14 Y 15; CON OTRAS CARACTERÍSTICAS FORMALES Y ESTILÍSTICAS

\begin{tabular}{|c|c|c|c|}
\hline 13 & 93r.-99r. & $\begin{array}{c}266-274 \\
\text { Comienza con } \\
\text { el final del } \\
\text { documento } \\
294\end{array}$ & $\begin{array}{l}\text { Gótica libraria redonda y } \\
\text { con mayor separación de } \\
\text { líneas y palabras. } \\
\text { Iniciales capitales pero sin } \\
\text { rúbrica. } \\
\text { Se copian suscripciones } \\
\text { reales y signos notariales, } \\
\text { pero muy esquemáticos }\end{array}$ \\
\hline 14 & $\begin{array}{l}100 \mathrm{r}-106 \mathrm{v} . \\
\text { El f. } 106 \mathrm{v} . \text { tiene una llamada } \\
\text { final: et tercia }\end{array}$ & $274-285$ & $\begin{array}{c}\text { Gótica libraría redonda y } \\
\text { con mayor separación de } \\
\text { líneas y palabras. } \\
\text { Iniciales capitales pero sin } \\
\text { rúbrica. } \\
\text { Se copian Crismones } \\
\text { iniciales, suscripciones } \\
\text { reales y signos notariales, } \\
\text { pero muy esquemáticos }\end{array}$ \\
\hline 15 & $\begin{array}{l}\text { f. } 107 \mathrm{r} .-114 \mathrm{v} \text {. } \\
\text { El f. 114v. tiene una llamada } \\
\text { final: Rodrico }\end{array}$ & $285-294$ & $\begin{array}{c}\text { Gótica libraría redonda y } \\
\text { con mayor separación de } \\
\text { líneas y palabras. } \\
\text { Iniciales capitales pero sin } \\
\text { rúbrica. } \\
\text { Se copian Crismones } \\
\text { iniciales, suscripciones } \\
\text { reales y signos notariales, } \\
\text { pero muy esquemáticos }\end{array}$ \\
\hline 16 & f.115r.-121v. & $295-325$ & $\begin{array}{l}\text { Gótica libraría } 1 \text { y gótica } \\
\text { documental } \\
\text { Iniciales capitales con } \\
\text { rúbrica. } \\
\text { Se copian algunos signos } \\
\text { notariales. }\end{array}$ \\
\hline 17 & $\begin{array}{c}\text { f.122r.-127v. } \\
\text { f.122r.: Incipit Itaque de illas } \\
\text { hereditates de Ambel quod } \\
\text { dedit Petro Taresa et meter } \\
\text { eius et alii bino homines uel } \\
\text { pertienciis (vid. n. 424) } \\
\text { Cortadas dos páginas finales } \\
\text { del cuadernillo } \\
\text { El f. 127r. está en blanco } \\
\text { El 127v.: Incipit liber de } \\
\text { hereditates que habaent } \\
\text { fratris militie Templi } \\
\text { Salomonis in Cesaraugusta } \\
\text { uel in Prouinciis suis. In } \\
\text { primis de illa dicamus que } \\
\text { dedit ad fratribus supradictis } \\
\text { Petrus comes }\end{array}$ & $326-340$ & $\begin{array}{c}\text { Gótica libraría } 1 \\
\text { Iniciales capitales con } \\
\text { rúbrica. } \\
\text { Se copian Crismones } \\
\text { iniciales, suscripciones } \\
\text { reales y signos notariales. }\end{array}$ \\
\hline 18 & $\begin{array}{l}\text { CUADERNILLO INSERTO, con } \\
\text { otras características: f.128r.- } \\
136 \mathrm{v} \text {. } \\
\text { hereditates que habaent } \\
\text { fratris militie Templi } \\
\text { Salomonis in Cesaraugusta }\end{array}$ & $\begin{array}{l}342-352 \text { y } 341 \\
\text { (en f. } 136 r .-v .)\end{array}$ & $\begin{array}{c}\text { Gótica libraría con un } \\
\text { cuerpo mayor } \\
\text { Se copian Crismones } \\
\text { iniciales, suscripciones } \\
\text { reales y signos notariales. } \\
\text { Iniciales capitales con } \\
\text { rúbrica. }\end{array}$ \\
\hline
\end{tabular}




\begin{tabular}{|c|c|c|c|}
\hline 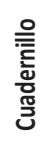 & Foliación & 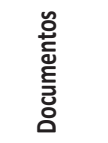 & Características formales \\
\hline 19 & $\begin{array}{c}\text { f.137r-143v. } \\
\text { Se supone que este } \\
\text { cuadernillo debía seguir al } \\
\text { cuadernillo } 4 \text {. } \\
\text { En el f. } 143 \text { r. figura el final } \\
\text { del documento } 93 \text {, que está } \\
\text { en el cuadernillo } 4 \text {. } \\
\text { El documento } 94 \text {, de } \\
\text { cuadernillo } 4 \text { acaba en el } \\
\text { f. } 143 r \text { r. } \\
\text { f.143v. en blanco }\end{array}$ & $353-367$ & $\begin{array}{c}\text { Letra Gótica. } \\
\text { Se copian Crismones } \\
\text { iniciales y algunas } \\
\text { suscripciones notariales. } \\
\text { La documentación se inicia } \\
\text { con inicial capital rubricada. }\end{array}$ \\
\hline 20 & $\begin{array}{c}144 r-151 v \text {. } \\
\text { f.146r.,149v. y } 151 v \text {. en } \\
\text { blanco }\end{array}$ & $368-385$ & $\begin{array}{c}\text { Gótica libraria } 1 \\
\text { Se copian algunas } \\
\text { suscripciones notariales y } \\
\text { signos regios. } \\
\text { La documentación se inicia } \\
\text { con inicial capital rubricada. }\end{array}$ \\
\hline 21 & f.152r.-158v. & $386-401$ & $\begin{array}{c}\text { Gótica libraria } 1 \\
\text { La documentación se inicia } \\
\text { con inicial capital rubricada. } \\
\text { Se copian algunas } \\
\text { suscripciones notariales y } \\
\text { signos regios }\end{array}$ \\
\hline 22 & $\begin{array}{c}\text { f.159r.-165v. } \\
\text { f. } 165 \mathrm{v} \text {. en blanco. }\end{array}$ & $402-420$ & $\begin{array}{c}\text { Gótica libraria } 1 \\
\text { La documentación se inicia } \\
\text { con inicial capital rubricada. } \\
\text { Se copian algunas } \\
\text { suscripciones notariales y } \\
\text { signos regios. } \\
\text { La mayor parte de los } \\
\text { registros son extractos } \\
\text { documentales. }\end{array}$ \\
\hline 23 & $\begin{array}{c}\text { f.166r.-177v. } \\
\text { doc. 421. Lista de cofrades } \\
\text { de Temple (Letra gótica } \\
\text { similar al cuadernillo 18). } \\
\text { doc. 422. Donaciones de los } \\
\text { cofrades (legra gótica con } \\
\text { cuerpo más pequeño) } \\
\text { f.171v. cambio del tipo de } \\
\text { letra } \\
\text { f.177v.: en el margen inferior } \\
\text { una llamada: hereditatem, } \\
\text { que hace referencia al folio } \\
\text { siguiente }\end{array}$ & $421-422$ & $\begin{array}{l}\text { Gótica con una caja de } \\
\text { escritura más grande } 1 \\
\text { Los documentos se inician } \\
\text { con una letra capital. }\end{array}$ \\
\hline 24 & $\begin{array}{c}\text { f.178r.-182 } \\
\text { Dos páginas cortadas entre } \\
\text { los f.79 y } 80 \\
\text { f.181r. cambio de letra }\end{array}$ & 422 & Gótica libraria \\
\hline 25 & $\begin{array}{l}\text { f.183r-184v. } \\
\text { f.184v. en blanco y sigue una } \\
\text { hoja en blanco y sin numerar }\end{array}$ & $423-424$ & $\begin{array}{l}\text { Gótica libraria grande para } \\
\text { el doc. } 423 \text { y más pequeña } \\
\text { para el doc. } 424 . \\
\text { Rúbricas para las iniciales } \\
\text { de los dos documentos }\end{array}$ \\
\hline 26 & $\begin{array}{c}\text { f.185r.-185v. } \\
\text { f.85r.: De comitissa Talesa }\end{array}$ & 425 & Gótica libraria grande \\
\hline 27 & $\begin{array}{c}\text { f.186r.-189v. } \\
\text { La relación documental } \\
\text { empieza en el f. 186v., que } \\
\text { continúa el documento } 425\end{array}$ & $425-427$ & Gótica de varios tamaños \\
\hline 28 & f.190r.199v. & $427-444$ & Gótica de varios tamaños \\
\hline
\end{tabular}

\section{BIBLIOGRAFÍA}

Alegría Suescun, D., Lopetegui Semperena, G. y Pescador Medrano, A. 1997. Archivo General de Navarra (1134-1194). San Sebastián: Eusko Ikaskuntza.

Alonso García, D. 1957. «Apuntes históricos de la villa de Alcanadre». Berceo 43: 199-214.

Álvarez Borge, I. 2008. Cambios y alianzas: la política regia en la frontera del Ebro en el reinado de Alfonso VIII de Castilla (1158-1214). Madrid: CSIC.

Álvarez-Coca González, M.a J. 2010. «La Orden de San Juan de Jerusalén en el Archivo Histórico Nacional: aproximación general a sus fuentes. El archivo del Gran Priorato de Navarra», Huarte de San Juan. Geografía e Historia 17: 97-118.

Bonet, M. 2007. "Historiografía e investigación sobre el Temple en la Corona de Aragón», en S. Merli (ed.), Milites Templi a 'Milites Templi'. II patrimonio monumentale e artistico dei Templari in Europa. Atti del Convegno internazionale (Perugia, Sala dei Notari, 6-7 maggio 2005): 39-86. Perugia: Volumnia Editrice.

Bonet Donato, M. 2014. «Identidad de las hospitalarias en la corona de Aragón (siglos XII y XIII)». Memoria y Civilización. Anuario de historia 17: 43-87.

Carraz, D. 2006. «Le cartulaire du Temple de Saint-Gilles, outil de gestión et instrument de pouvoir», en D. Le Blévec (dir.), Les cartulaires méridionaux (actes du colloque de Béziers les 20 et 21 septembre 2002 par le Centre historique de recherches et d'études médiévales sur la Méditerranée occidentale): 145-162. París: Bibliothèque de I'École des Chartes.

Carraz, D. 2011. "La territorialisation de la seigneurie monastique: les commanderies provençales du Temple (XII ${ }^{\mathrm{e}} \mathrm{XIII}{ }^{\mathrm{e}}$ siècle)", Mélanges de l'École française de Rome 123/2: 443-460.

Cartulario del Temple de Huesca. 1985. Gargallo Moya, A., Iranzo Muñio, M.a T. y Sánchez Usón, M. a J. (eds. e índices). Zaragoza: Anubar.

Castro, J. R. 1941. "Juan Antonio Fernández. Archivero de la Orden de Santiago». Príncipe de Viana 2: 95-122.

Chastang, P. 2006. «Cartulaires, cartularisation et scripturalité médiévale: la sructuration d'un nouveau champ de recherche». Cahiers de civilisation médiévale- La médiévistique au XXe siècle. Bilan et perspectives 193: 21-31.

Cruz Herranz, L. M. de la. 2011. "Javierre y Mur, Áurea Lucinda», en Diccionario Biográfico Español. Madrid: Real Academia de la Historia, vol. XXVII: 737-738.

De Albon, M. 1913. Cartulaire Général de l'ordre du Temple (1119?1150). Paris: Libraire Ancienne, Honoré Champion éditeur.

Delaville Le Roulx, J. 1893. "Les archives de I'ordre de l'Hôpital dans la Péninsule Ibérique». Nouvelles Archives des Missions scientifiques et littéraires 4: 1-283.

Escalona, J. et Sirantoine, H. 2013. «Produit culturel et instrument de pouvoir», en J. Escalona et $\mathrm{H}$. Sirantoine (dirs.), Chartes et Cartulaires comme instruments de pouvoir. Espagne et Occident chrétien (VIII'-XII siècles): 9-14. Tolouse: CSIC-CNSR-Université de Tolouse-Le Mirail.

Forey, A. 1973. The Templars in the Corona de Aragón. London: Oxford University Press.

Fortún Pérez de Ciriza, L. J. 1982. «Colección de 'fueros menores' de Navarra y otros privilegios locales (I)». Príncipe de Viana 165: 273-348.

Fortún Pérez de Ciriza, L. J. 1998. «Del reino de Pamplona al reino de Navarra (1134-1217)», en Historia de España Ramón Menéndez Pidal. IX. La reconquista y el proceso de diferenciación política (1035-1217): 607-660. Madrid: Espasa-Calpe.

Fortún Pérez de Ciriza, L. J. 2000. «La quiebra de la soberanía navarra el Álava, Guipúzcoa y el Duranguesado (1199-1200)». Revista internacional de estudios vascos 45: 439-494.

García Edo, V. 2010. «Una aproximación a los cartularios templarios en la Corona de Aragón», en J. M.a Sans i Travé y J. Serrano Daura (coord.), Actes de les Jornades Internacionals d'Estudi sobre els Orígens i l'Expansió de l'Orde del Temple a la Corona d'Aragó (1120-1200): Tortosa, 7, 8 i 9 de maig de 2004: 429-448. Tarragona: Diputación de Tarragona. 
García Larragueta, S. 1981. «El Temple en Navarra». Anuario de Estudios Medievales 11: 635-661.

Gargallo Moya, A. J., Iranzo Muñío, M.a T. y Sánchez Usón, M.ạ J. 1981. "Aportación al estudio del dominio del Temple de Huesca», Aragón en la Edad Media 4: 7-56.

Guijarro Santos, P. 2007. «El archivo del marquesado de San Adrián durante la Ilustración: organización, fin, utilidad y uso». Príncipe de Viana 68: 977-1010.

Guijarro Santos, P. 2009. Los Deseosos del Bien Público: protagonistas, mentalidades y proyectos en Tudela durante la Ilustración (17501808). Pamplona: Universidad de Navarra, tesis doctoral inédita, 2009.

Gutiérrez del Arroyo, C. 1992. Catálogo de la documentación Navarra de la Orden de San Juan de Jerusalén en el Archivo Histórico Nacional (siglos XII-XIX). Pamplona: Gobierno de Navarra.

Javierre Mur, A. L. 1947-1948. «El archivo de San Juan de los Panetes de Zaragoza. Una fuente interesante para el estudio de la Edad Media Aragonesa». Estudios de Edad Media de la Corona de Aragón 3: 157-192.

Lacarra, J. M. a 1946. «Documentos para el estudio de la reconquista y repoblación del valle del Ebro (primera serie)». Estudios de Edad Media de la Corona de Aragón 2: 469-574.

Lacarra, J. M.a 1947-1948. «Documentos para el estudio de la reconquista y repoblación del valle del Ebro (segunda serie)». Estudios de Edad Media de la Corona de Aragón 3: 449-727.

Lacarra, J. M.a 1952. "Documentos para el estudio de la reconquista y repoblación del valle del Ebro (tercera serie)». Estudios de Edad Media de la Corona de Aragón 5: 511-668.

Laguna Campos, J. 1999. «Notas sobre algunos rasgos romances en el Cartulario del Temple de Huesca», en M. Pérez González (coord.), Actas del II Congreso Hispánico de Latín Medieval (León, 11-14 de noviembre de 1997), Vol. 2: 589-598. León: Universidad de León.

Lapeña Paúl, A. I. 1978. Documentos de la encomienda templaria de Novillas. Zaragoza: Universidad de Zaragoza, tesis de licenciatura (inédita).

Lapeña Paúl, A. I. 1978. «La encomienda de la orden del Temple en Novillas (siglo XII)», Cuadernos de Estudios Borjanos 3: 95-169.

Le Blévec, D. y Venturini, A. 1993. «Cartulaires des Ordres Militaires. XII $-\mathrm{XIII}$ siècles (Provence occidentale- Basse vallée du Rhône)», en O. Guyotjeannin, L. Morelle, M. Parisse (eds.), Les Cartulaires, (actes de la table ronde organisée par l'École nationale des chartes et le GDR 121 du CNRS, Paris, 5-7 décembre 1991): 458-459. Paris: École des Chartes.

Ledesma Rubio, M.a L. 1982. Templarios y Hospitalarios en el Reino de Aragón. Zaragoza: Editorial Guara.

Ledesma Rubio, M.a L. 1994. Las órdenes militares en Aragón, Caja de Ahorros de la Inmaculada de Aragón. Zaragoza: Caja de Ahorros de la Inmaculada de Aragón.
Lema Pueyo. J. A. 1990. Colección Diplomática de Alfonso I de Aragón y Pamplona (1104-1134). San Sebastián: Eusko Ikaskuntza.

Madrid Medina, A. 2012. El maestre Juan Fernández de Heredia y el Cartulario Magno de la Castellanía de Amposta. Zaragoza: Institución Fernando El Católico.

Martín Duque, A. J. 2000. "Sancho el Sabio y el fuero de Vitoria», en Vitoria en la Edad Media: 3-25. Vitoria: Ayuntamiento de Vitoria

Martínez Díez, G. 1993. Los templarios en la corona de Castilla. Burgos: La Olmeda.

Pavón Benito, J. 2005. «El Cister y la monarquía navarra (siglos XIIXIII)». Cistercium, 238: 379-421.

Pavón, J. y Bonet, M. 2010. «La documentación medieval del priorato navarro de la orden de San Juan de Jerusalén en el Archivo Histórico Nacional». Huarte de San Juan. Geografía e Historia 17: 209-240.

Remírez Vallejo, S. 2009. "Los Señores de Cortes: una familia nobiliaria de cofrades y benefactores de la Orden del Temple en la Ribera de Navarra». Revista del Centro de Estudios Merindad de Tudela, 17: 97-127.

Remírez Vallejo, S. 2016. Los templarios en Cintruénigo. Zaragoza: Universidad de Zaragoza, tesis doctoral (inédita).

Remírez Vallejo, S., Tambo Moros, J. y Martínez, A. 2009. El Castillo de Cintruénigo (Siglos XII-XVI). Cintruénigo: Ayuntamiento de Cintruénigo.

Ripert-Monclar, Marquis d. 1907. Cartulaire de la commanderie de Richerenches de l'ordre du Temple (1136-1214). Avignon-Paris: F. Seguin- H. Champion.

Sánchez, A. B. y Domínguez, J. 2000. "Las escrituras góticas», en A. Riesco Terrero (ed.), Introducción a la Paleografía y a la Diplomática General: 111-133. Madrid: Síntesis.

Sánchez Mairena, A. 2012. «Propuestas metodológicas para el estudio de los cartularios medievales», en B. Arízaga Bolumburu (ed.), Mundos medievales: espacios, sociedades y poder. Homenaje al profesor José Ángel García de Cortázar y Ruiz de Aguirre, Vol. 1: 217-230. Santander: Editorial de la Universidad de Cantabria.

Sans i Travé, J. M.a y Pladevall i Font, A. 2006. Arnau de Torroja: un català mestre major de l'Orde del Temple (1118/1120?-1184). Discurs llegit el dia 19 de desembre de 2006 en l'acte de recepció pública de Josep M. Sans i Travé a la Reial Acadèmia de Bones Lletres de Barcelona i contestació de l'acadèmic numerari. Barcelona: Reial Acadèmia de Bones Lletres de Barcelona.

Torre Gonzalo, S. de la (ed.). 2009. El Cartulario de la Encomienda Templaria de Castellote (Teruel), 1184-1283. Zaragoza: Universidad de Zaragoza.

Ubieto Arteta, A. 1973. Los «tenentes» en Aragón y Navarra en los siglos XI y XII. Valencia: Anubar.

Ubieto Arteta, A. 1980. "Cofrades aragoneses y navarros de la milicia del Temple (siglo XII). Aspectos socio-económicos». Aragón en la Edad Media 3: 29-93. 